\title{
The neurological outcome of acute spinal cord injury in a neurosurgical hospital of a developing country
}

\author{
Albert VB Brasil ${ }^{1}$ and Danilo Gonçalves Coelho ${ }^{2}$ \\ ${ }^{1}$ Hospital São José-ISCMPA, Av. Cavalhada 5205 Casa 57, 91751-830 Porto Alegre, RS, Brazil; ${ }^{2}$ R. Guilherme \\ Alves 1602, 90680-000 Porto Alegre, RS, Brazil
}

The neurological outcome of 146 patients who survived spinal cord injury in a neurosurgical hospital of a developing country, were compared to those reported from Stoke Mandeville, UK. The average recuperation in the two groups was similar.

Keywords: spinal cord injury; neurological outcome; developing country

\section{Introduction}

The neurological results of the treatment of spinal cord injury have not changed during the last decades. ${ }^{1}$ According to many authors, good results are obtained in sophisticated medical units devoted exclusively to this type of disease. ${ }^{2-6}$

For the last 9 years, the authors have managed acutely spinal cord injured patients in a general neurosurgical hospital located in a developing country. This hospital has no Emergency Room dedicated to trauma. Patients are referred from other hospitals in the city and neighbouring areas. No facility specifically designed to spinal cord injured patients is available in this hospital. The goal of the institution in this area is to afford initial care, giving patients the necessary conditions to be sent home and to perform rehabilitation as outpatients.

One can assume that the neurological results obtained in such circumstances may be worse than those obtained in specialised spinal cord injury units. This study compares the neurological results collected prospectively at Hospital São José (HSJ, Brazil) with those presented in the largest ever reported series of spinal cord injured patients evaluated by the Frankel scale - the series from Stoke-Mandeville (SM, UK). ${ }^{7}$

\section{Patients and methods}

All patients sustaining a traumatic spinal cord injury admitted to the care of the authors between August 1986 and July 1995 were studied. There were 164 patients. One hundred thirty four were male. The age distribution is presented in Table 1 and the causes of trauma in Table 2. The median time between trauma and admission was 3 days.

Upon admission patients were submitted to full neurological examination including the perineum. The

Correspondence: AVB Brasil
Frankel scale was used for initial and follow up evaluation (Figure 1). The median time of hospitalisation was 19 days. Eighteen patients (10.9\%) died (15/ 100 cervical, 2/27 thoracic and 1/37 thoracolumbar) and were eliminated from the neurological outcome study. The length of follow up is presented in Table 3. Final neurological result was the one found upon last examination. In those who were lost to follow up (47 patients), the final result was the one found in the moment of discharge.

A detailed description of the treatment of each type of lesion will not be reported. The general goals of treatment were: to reduce vertebral dislocation, to provide spinal stabilisation and to decompress the spinal cord. Closed reduction was initially attempted in cervical dislocation. In the case of failure, reduction was obtained surgically. In the thoracolumbar segment dislocations were treated surgically. Spinal instability (White's criteria ${ }^{8}$ for the cervical spine and Denis' criteria ${ }^{9}$ for the thoracolumbar spine) was usually treated surgically if significant ligamentous injury was found, or if an operation had been previously indicated for other reasons. When spinal instability was mainly determined by osseous lesion, the treatment choice moved to external immobilisation, as long as the patient had sufficient skin sensibility to tolerate it. When spinal cord compression persisted after reduction a decision was made as to the necessity of decompression. In cases of complete spinal cord lesion it was never indicated. In those patients with incomplete spinal cord injuries a time of observation was allowed. In case of neurological stabilisation a decompression was indicated, usually from the anterior approach. In case of progressive and satisfactory recuperation, even in the presence of persistent spinal cord compression, no decompressive procedure was undertaken. Under these guidelines 106 patients were treated surgically. 
Table 1 Patient distribution according to age

\begin{tabular}{ll}
\hline Age (years) & $N$ \\
\hline $0-9$ & 01 \\
$10-19$ & 23 \\
$20-29$ & 43 \\
$30-39$ & 41 \\
$40-49$ & 25 \\
$50-59$ & 20 \\
$60-69$ & 10 \\
over 70 & 01 \\
Total & 164 \\
\hline
\end{tabular}

Table 2 Causes of trauma

\begin{tabular}{ll}
\hline Causes & $N$ \\
\hline Vehicle accident & 62 \\
Fall from height & 42 \\
Gunshot & 19 \\
Water sports & 12 \\
Other & 29 \\
Total & 164 \\
\hline
\end{tabular}

\begin{tabular}{|c|c|}
\hline A & Complete sensory-motor loss \\
\hline B & Sensory preservation only \\
\hline C & Motor useless preservation \\
\hline D & Motor useful preservation \\
\hline E & Normal \\
\hline
\end{tabular}

Figure 1. Frankel scale

Table 3 Length of follow up

\begin{tabular}{ll}
\hline Time & $N$ \\
\hline 3 months & 99 \\
6 months & 84 \\
9 months & 58 \\
12 months 12 months & 42 \\
more than 12 . & 31 \\
\hline
\end{tabular}

In order to allow comparison with the StokeMandeville series, surviving patients were subdivided into three categories: cervical, 85 patients; thoracic (T1-T10), 25 patients; and thoracolumbar (T11-L1), 36 patients. The correlation between initial and final evaluation from HSJ and SM patients are presented side by side in Tables 4, 5 and 6 . Since the number of patients with complete and incomplete lesions differed significantly in the two groups, the comparisons between neurological recoveries was made within each sub-category (Cervical grade A, Thoracic grade $\mathrm{C}$, etc), neurological recovery was estimated by the method utilised by Young. ${ }^{10}$ Net average neurological recovery (NANR) in Frankel grades was calculated by subtracting the total number of degrees lost and adding the total number of degrees gained in each sub-category, and dividing this value by the total number of patients in this sub-category. The $t$-test was used for statistical analysis. The significance level chosen was $P<0.05$.

\section{Results}

The comparisons between the net average neurological recoveries obtained at HSJ and SM are demonstrated in Tables 7, 8 and 9. No statistically significant difference existed between all but one sub-category. The only exception occurred in patients sustaining cervical lesions grade D. In this situation the recovery at HSJ was superior to SM.

\section{Discussion}

The Frankel scale is not the ideal instrument to make comparisons between different patient series. ${ }^{11}$ The arbitrary division between 'useful' and 'useless' motor recovery (respectively grades D and C) allows many different interpretations. Scales-based on sharper quantitative evaluation have been reported in the literature. $^{12,13}$ So far, the best system available seems to be the International Standards proposed by ASIA and IMSOP in 1994, after exhaustive debate among specialists in this field. ${ }^{14}$ Nevertheless, the utility of the Frankel scale can not be overlooked. This is testified by the fact that it is an integrant part of the above mentioned International Standards. Data obtained from clinical series that used the Frankel scale are able to answer the main questions posed by patients

Table 4 Initial $\times$ final grades. Cervical lesions

\begin{tabular}{|c|c|c|c|c|c|c|c|c|c|c|c|}
\hline & & & & & & & & & & & \\
\hline & $\begin{array}{c}\text { Initial } \\
\mathrm{A}\end{array}$ & B & $\mathrm{C}$ & $\mathrm{D}$ & $\begin{array}{c}\text { Final } \\
\text { E }\end{array}$ & Initial & A & B & $\mathrm{C}$ & D & $\begin{array}{c}\text { Final } \\
\text { E }\end{array}$ \\
\hline A & 17 & 00 & 01 & 02 & 00 & A & 81 & 21 & 10 & 11 & 00 \\
\hline $\mathrm{B}$ & 00 & 03 & 02 & 01 & 04 & B & 03 & 09 & 02 & 14 & 05 \\
\hline $\mathrm{C}$ & 00 & 00 & 11 & 10 & 12 & C & 00 & 01 & 04 & 11 & 05 \\
\hline $\mathrm{D}$ & 00 & 00 & 00 & 07 & 15 & $\mathrm{D}$ & 00 & 00 & 00 & 30 & 11 \\
\hline
\end{tabular}


Table 5 Initial $\times$ final grades. Thoracic lesions $(\mathrm{T} 1-\mathrm{T} 10)$

\begin{tabular}{|c|c|c|c|c|c|c|c|c|c|c|c|}
\hline & & & & & & & & & & & \\
\hline & $\begin{array}{c}\text { Initial } \\
\text { A }\end{array}$ & B & C & D & $\begin{array}{c}\text { Final } \\
\text { E }\end{array}$ & Initial & A & B & C & D & $\begin{array}{c}\text { Final } \\
\text { E }\end{array}$ \\
\hline A & 19 & 00 & 00 & 00 & 00 & A & 114 & 11 & 02 & 07 & 01 \\
\hline B & 00 & 00 & 00 & 00 & 00 & B & 00 & 06 & 02 & 05 & 02 \\
\hline $\mathrm{C}$ & 00 & 00 & 01 & 02 & 03 & C & 00 & 00 & 01 & 01 & 00 \\
\hline $\mathrm{D}$ & 00 & 00 & 00 & 00 & 00 & $\mathrm{D}$ & 00 & 00 & 00 & 04 & 09 \\
\hline
\end{tabular}

Table 6 Initial $\times$ final grades. Thoracolumbar lesions $(\mathrm{T} 11-\mathrm{L} 1)$

\begin{tabular}{|c|c|c|c|c|c|c|c|c|c|c|c|}
\hline & & & & & & & & & & & \\
\hline & $\begin{array}{c}\text { Initial } \\
\mathrm{A}\end{array}$ & B & $\mathrm{C}$ & D & $\begin{array}{c}\text { Final } \\
\text { E }\end{array}$ & Initial & A & B & C & D & $\begin{array}{c}\text { Final } \\
\mathrm{E}\end{array}$ \\
\hline A & 14 & 01 & 02 & 00 & 00 & A & 102 & 12 & 02 & 10 & 00 \\
\hline B & 00 & 02 & 01 & 01 & 00 & B & 01 & 04 & 02 & 15 & 02 \\
\hline $\mathrm{C}$ & 00 & 00 & 04 & 06 & 03 & $\mathrm{C}$ & 01 & 00 & 04 & 16 & 04 \\
\hline $\mathrm{D}$ & 00 & 00 & 00 & 01 & 01 & D & 00 & 00 & 00 & 18 & 09 \\
\hline
\end{tabular}

Table 7 Comparison between Net Average Neurological Recovery (NANR) from HSJ and SM. Cervical

\begin{tabular}{lllll}
\hline Grade & $\begin{array}{l}\text { HSJ } \\
(N A N R)\end{array}$ & $\begin{array}{l}\text { SM } \\
(N A N R)\end{array}$ & $t$ & $\begin{array}{l}\text { Significance } \\
(\mathrm{P}<0.05)\end{array}$ \\
$\mathrm{A}$ & 0.40 & 0.60 & 1.96 & $\mathrm{NS}$ \\
$\mathrm{B}$ & 1.60 & 1.27 & 1.96 & $\mathrm{NS}$ \\
$\mathrm{C}$ & 1.03 & 0.95 & 1.96 & $\mathrm{NS}$ \\
$\mathrm{D}$ & 0.68 & 0.26 & 1.96 & Significant \\
\hline
\end{tabular}

$\mathrm{NS}=$ Not significant

Table 8 Comparison between Net Average Neurological Recovery (NANR) from HSJ and SM Thoracic (T1-T10)

\begin{tabular}{lllll}
\hline Grade & $\begin{array}{l}\text { HSJ } \\
(N A N R)\end{array}$ & $\begin{array}{l}S M \\
(N A N R)\end{array}$ & $t$ & $\begin{array}{l}\text { Significance } \\
(\mathrm{P}<0.05)\end{array}$ \\
\hline A & 0.0 & 0.29 & 1.96 & NS \\
B & - & - & - & - \\
C & 1.33 & 0.5 & 2.36 & NS \\
D & - & - & - & - \\
\hline
\end{tabular}

$\mathrm{NS}=$ Not significant

Table 9 Comparison between Net Average Neurological Recovery (NANR) from HSJ and SM. Thoracolumbar (T11-L1)

\begin{tabular}{lllll}
\hline Grade & $\begin{array}{l}\text { HSJ } \\
(N A N R)\end{array}$ & $\begin{array}{l}S M \\
(N A N R)\end{array}$ & $t$ & $\begin{array}{l}\text { Significance } \\
(\mathrm{P}<0.05)\end{array}$ \\
\hline $\mathrm{A}$ & 0.29 & 0.36 & 1.96 & $\mathrm{NS}$ \\
$\mathrm{B}$ & 0.75 & 1.54 & 2.06 & $\mathrm{NS}$ \\
$\mathrm{C}$ & 0.92 & 0.88 & 1.96 & $\mathrm{NS}$ \\
$\mathrm{D}$ & 0.50 & 0.33 & 2.06 & $\mathrm{NS}$ \\
\hline
\end{tabular}

and families in the moment of admission: "will I ever move my legs (grade C)?', 'is he ever going to walk even with some aid (grade D)?', 'will I ever be normal again (grade E)?' While numerical scales can show to researchers the precise differences between therapeutic regimens, the neurological scale remains the best tool to deal with patients concerns.

Comparisons between series evaluated by the neurological scale were reported. ${ }^{10,15,16}$ The choice of the statistical approach depends on the demographic differences and similarities of the groups studied. In 1978 Young compared his personal experience with Frankel's series. ${ }^{10}$ Due to the extreme similarity of the two populations, the comparison was simply made between the three basic groups: cervical, thoracic and thoracolumbar. In the present study, the proportion of complete and incomplete cases within each category differs significantly from Stoke Mandeville. Comparisons, therefore, were made between each 'subcategory'. The net average neurological recoveries differed very little, sometimes superior in HSJ, sometimes superior in SM. These differences, however, were almost never statistically significant.

Global mortality was $10.9 \%$. This mortality, specially in cervical cases $(15 \%)$, lies above the one found in recently reported studies. ${ }^{17,18}$ The vast majority of deaths occurred among cervical complete cases. A higher mortality in this type of patient suggests intensive care management difficulties and is strongly related to economical factors.

The treatment protocol is not the focus of this study, but deserves some comments. The approach lies midway between radically surgical and radically conservative ones. From the neurological standpoint neither the surgical nor the conservative approach were ever demonstrated to be superior. Therefore no 
difference or similarity of neurological results can be attributed to the fact that HSJ series comprised a large number of surgical cases.

The recommendation that spinal injured patients should be managed in specialised spinal units is frequently found. ${ }^{2-6}$ Deficient hospital conditions have been blamed for bad management results. ${ }^{19}$ Developing countries usually make little investments on the management of complex pathologies. In this context, spinal injured patients from developing countries are usually managed in general or neurosurgical hospitals. The initial hypothesis of this study was that a worse neurological outcome could be expected from spinal cord injured patients treated in a general neurosurgical hospital of a developing country. Results have shown a mortality that is still high. Among survivors, however, the management offered to these patients, did not worsen their neurological prognosis.

\section{Conclusions}

The neurological recovery of surviving spinal cord injured patients treated in a neurosurgical hospital of a developing country can be similar to the one found in a specialised spinal cord injury center.

\section{Acknowledgements}

We thank Felipe Cecchini for his dedicated help in the preparation of this manuscript.

\section{References}

1 Bracken MB, Shepard MJ, Collins WF et al. A randomised, controlled trial of Methylprednisolone and naloxone in the treatment of acute spinal-cord injury. $N$ Engl J Med 1990; 322: $1405-1411$

2 Wagner F, Zusman EE. Neurological recovery following traumatic spinal cord injury. In: Piepmeier JM. (ed). The Outcome Following Traumatic Spinal Cord Injury. Futura Publishing Co, Mount Kisco, NY. 1992, p 1.
3 Bedbrock GM. Spinal injuries with paraplegia and tetraplegia. $J$ Bone Joint Surg 1979; 61-B: 267-264.

4 Botterel EH, Jousse AT, Kraus AS et al. A model for the future care of acute spinal cord injuries. Can J Neur Sci 1975; 2: 361 380 .

5 Guttmann I. Editorial to 15th Volume. Paraplegia 1977; 15: 1 -2.

6 Apple DF. Spinal cord injury rehabilitation. In: Rothman RH, Simeone FA. (eds) The Spine. 3rd ed. WB Saunders Co, Philadelphia. 1992, p 1225.

7 Frankel HL, Hancock DO, Hyslop G et al. The value of postural reduction in the management of closed injuries of the spine with paraplegia and tetraplegia. Part 1. Paraplegia 1969; 7: 179-192.

8 White AA, Southwick WO, Panjabi MM. Clinical instability in the lower cervical spine. Spine 1976; 1: 15-27.

9 Denis F. The three column spine and its significance in the classification of acute spinal injuries. Spine 1983; 8: 817-831.

10 Young JS, Dexter WR. Neurological recovery distal to the zone of injury in 172 cases of closed, traumatic spinal cord injury. Paraplegia 1978; 16: $39-49$.

11 Bohlman HH, Ducker TB. Spine and spinal cord injuries. In: Rothman RH, Simeone FA. (eds) The Spine. 3rd ed. WB Saunders Co, Philadelphia 1992, p 973.

12 Lucas JT, Ducker TB. Motor classification of spinal cord injuries with mobility, morbidity and recovery indices. Am Surg 1979; 45: $151-158$.

13 Cherazi B, Wagner Jr FC, Collins Jr WF, Freeman DH. A scale for the evaluation of spinal cord injury. J Neurosurg 1981; 54: $310-315$.

14 Ditunno JF, Young WH, Creasey G. The international standards booklet for neurological and neurological classification of spinal cord injury. Paraplegia 1994; 32: 70-80.

15 Maynard FM, Reynolds GG, Fountain S et al. Neurological prognosis after traumatic quadriplegia. J Neurosurg 1979; 50: $611-616$.

16 Burke DC, Murray DD. The management of thoracic and thoraco-lumbar injuries of the spine with neurological involvement. J Bone Joint Surg 1976; 58-B: $72-78$.

17 Levi L, Wolf A, Rigamonti D et al. Anterior decompression in cervical spine trauma: does the timing of surgery affect the outcome? Neurosurg 1991; 29: 216-222.

18 Hadley MN, Fitzpatrick BC, Sonntag VKH, Browner CM. Facet fracture-dislocation of the cervical spine. Neurosurg 1992; 30: $661-666$.

19 Chacko V, Joseph B, Mohanty SP, Jacob T. Management of spinal cord injury in a general hospital in rural India. Paraplegia 1986; 24: $330-335$. 